\title{
Structure Elucidation of Sch 725674 from Aspergillus sp.
}

\author{
Shu-Wei Yang, Tze-Ming Chan, Joseph Terracciano, David Loebenberg, Mahesh Patel, \\ Min Chu
}

Received: June 11, 2005 / Accepted: August 12, 2005

(C) Japan Antibiotics Research Association

\begin{abstract}
A new macrolide Sch725674 (1) was isolated and identified from the culture of an Aspergillus sp. The structure elucidation of $\mathbf{1}$ was accomplished based on extensive NMR spectroscopic analyses. Compound 1 showed inhibitory activity against Saccharomyces cerevisiae (PM503) and Candida albicans (C43) with MICs of 8 and $32 \mu \mathrm{g} / \mathrm{ml}$, respectively.
\end{abstract}

Keywords antifungal, antimicrobial, structure elucidation, Sch 725674

In the course of our continuing search for novel antimicrobial agents [1 8], we have isolated a novel antifungal macrolide, Sch 725674 (1), from an Aspergillus sp. culture (SPRI-0836). Sch725674 was identified as a new 14-membered macrocyclic lactone based on extensive NMR spectroscopic analyses. In this paper, we describe the isolation and the structure elucidation of 1 . The antimicrobial activity of $\mathbf{1}$ against fungal pathogens is also reported.

Fermentation studies of the Aspergillus sp. culture SPRI0836 were conducted in shake flasks. Stock cultures were maintained as frozen whole broths at $-80^{\circ} \mathrm{C}$ in a final concentration of $10 \%$ glycerol. The inoculum medium contained Proteus Peptone ( $5 \mathrm{~g} /$ liter $), \mathrm{NaCl}$ ( $5 \mathrm{~g} /$ liter), $\mathrm{KH}_{2} \mathrm{PO}_{4}$ ( $5 \mathrm{~g} /$ liter $)$, yeast extract ( $\mathrm{g} /$ liter), cerelose (20 g/liter), soybean grits ( $5 \mathrm{~g} /$ liter), antifoam ( $1 \mathrm{ml} / \mathrm{liter})$, and distilled $\mathrm{H}_{2} \mathrm{O}$ (1 liter). The $\mathrm{pH}$ was adjusted to 7.2 prior to autoclaving. Each $250 \mathrm{ml}$ Erlenmeyer flask containing
$70 \mathrm{ml}$ of this medium was inoculated with $2 \mathrm{ml}$ of the stock culture. The flasks were incubated at $24^{\circ} \mathrm{C}$ on a rotary shaker at $250 \mathrm{rpm}$ for 96 hours. This seed culture $(2.5 \mathrm{ml})$ was used to inoculate a second stage seed in $250 \mathrm{ml}$ Erlenmeyer flasks, each containing $70 \mathrm{ml}$ of the same seed medium and the flasks were incubated as above for 96 hours.

This second stage seed was then used to inoculate the fermentation medium at $5 \% \mathrm{v} / \mathrm{v}$. The fermentation was carried out in 2 liter Erlenmeyer flasks, each containing $350 \mathrm{ml}$ of the fermentation medium, containing oat flour (20 g/liter), soy flour (20 g/liter), yeast extract (2 g/liter), corn steep powder ( $5 \mathrm{~g} /$ liter $), \mathrm{K}_{2} \mathrm{HPO}_{4}(11 \mathrm{~g} /$ liter $), \mathrm{KH}_{2} \mathrm{PO}_{4}$ ( $4 \mathrm{~g} /$ liter), and distilled $\mathrm{H}_{2} \mathrm{O}$ (1 liter). The flasks were incubated at $24^{\circ} \mathrm{C}$ on a rotary shaker at $250 \mathrm{rpm}$ for 120 hours.

The harvested fermentation broth (10 liter) was stirred with $2 \mathrm{~kg}$ of $\mathrm{NaCl}$ and 20 liters of acetonitrile (MeCN) for 15 minutes. The organic layer was separated and concentrated to a slurry in vacuo. The slurry material was absorbed onto the polymeric resin, CG161 ( $200 \mathrm{ml}$, Tosoh Biosep LLC, Montgomeryville, PA, USA) and the salts and small hydrophilics were washed out with 20 liters of water. Then, the absorbed organic material was eluted with $85 \%$ aq. $\mathrm{MeOH}$ (4 liter) to yield $\sim 1.5 \mathrm{~g}$ of dried material after removing solvent in vacuo. This organic material was purified on a semi-preparative ODS-A HPLC column (YMC, $120 \AA$, S-7, $20 \mathrm{~mm} \times 250 \mathrm{~mm}$ ). The column was eluted with a gradient of $\mathrm{MeCN}-\mathrm{H}_{2} \mathrm{O}$ : 5 100\% $\mathrm{MeCN}$ in 35 minutes, and then isocratically with $100 \%$ $\mathrm{MeCN}$ for another 15 minutes, with a flow rate of
S.-W. Yang (Corresponding author), T.-M. Chan, J. Terracciano, D. Loebenberg, M. Patel, M. Chu: ScheringPlough Research Institute, 2015 Galloping Hill Road, Kenilworth, NJ 07033, USA, E-mail: shu-wei.yang@spcorp.com
Present address: M. Chu, J. Terracciano: Cubist Pharmaceuticals, Inc. 65 Hayden Ave. Lexington, MA 02421, USA 
Table 1 NMR spectral data for compound 1 in $\mathrm{CD}_{3} \mathrm{OD}^{\mathrm{a}}$

\begin{tabular}{clll}
\hline $\mathrm{C} / \mathrm{H}$ no. & \multicolumn{1}{c}{${ }^{1} \mathrm{H}(\delta)$} & ${ }^{13} \mathrm{C}(\delta)$ & HSOC-TOCSY \\
\hline 1 & & $168.4 \mathrm{~s}$ & \\
2 & $6.07, \mathrm{dd}, 15.8,1.6$ & $123.1 \mathrm{~d}$ & $\mathrm{C}-3$ \\
3 & $6.86, \mathrm{dd}, 15.8,6.0$ & $149.3 \mathrm{~d}$ & $\mathrm{C}-2, \mathrm{C}-4$ \\
4 & $4.48, \mathrm{ddd}, 6.0,3.0,1.6$ & $76.0 \mathrm{~d}$ & $\mathrm{C}-2^{\mathrm{b}}, \mathrm{C}-5$ \\
5 & $3.84, \mathrm{ddd}, 6.0,4.7,3.0$ & $72.9 \mathrm{~d}$ & $\mathrm{C}-6$ \\
6 & $1.82, \mathrm{ddd}, 14.7,6.5,6.0$ & $38.3 \mathrm{t}$ & $\mathrm{C}-5, \mathrm{C}-7$ \\
& $1.65, \mathrm{~m}$ & & \\
7 & $3.98, \mathrm{q}, 6.5$ & $69.5 \mathrm{~d}$ & $\mathrm{C}-6, \mathrm{C}-8$ \\
9 & $1.36, \mathrm{~m}$ & $36.8 \mathrm{t}$ & \\
10 & $1.19, \mathrm{~m} ; 1.37, \mathrm{~m}$ & $25.8 \mathrm{t}$ & $\mathrm{C}-8, \mathrm{C}-10$ \\
11 & $1.15, \mathrm{~m} ; 1.40, \mathrm{~m}$ & $29.5 \mathrm{t}$ & \\
12 & $1.19, \mathrm{~m} ; 1.45, \mathrm{~m}$ & $27.0 \mathrm{t}$ & $\mathrm{C} 12$ \\
13 & $1.54, \mathrm{~m} ; 1.70, \mathrm{~m}$ & $34.1 \mathrm{t}$ & $\mathrm{C} 10^{\mathrm{b}}, \mathrm{C}-11, \mathrm{C}-13$ \\
14 & $4.94, \mathrm{dddd}, 9.8,7.5,5.0,2.2$ & $77.6 \mathrm{~d}$ & $\mathrm{C}-12, \mathrm{C}-14$ \\
15 & $1.57, \mathrm{~m} ; 1.61, \mathrm{~m}$ & $36.5 \mathrm{t}$ & $\mathrm{C}-13, \mathrm{C}-15, \mathrm{C}-16^{\mathrm{b}}$ \\
16 & $1.32, \mathrm{~m}$ & $26.4 \mathrm{t}$ & $\mathrm{C}-13^{\mathrm{b}}$ \\
17 & $1.30, \mathrm{~m}$ & $32.9 \mathrm{t}$ & \\
18 & $1.31, \mathrm{~m}$ & $23.8 \mathrm{t}$ & $\mathrm{C}-18$ \\
$\mathrm{NH}$ & $0.89, \mathrm{t}, 6.8$ & $14.5 \mathrm{q}$ & $\mathrm{C}-16^{\mathrm{b}}, \mathrm{C}-17$ \\
\hline $\mathrm{NH}$ & & & \\
\hline
\end{tabular}

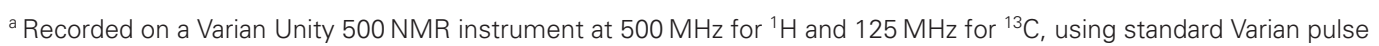
sequence programs (VNMR Version 6.1 Software). $\delta$ in ppm; $J$ in $\mathrm{Hz}$.

${ }^{\mathrm{b}}$ Three-bond correlation

$15 \mathrm{ml} /$ minute and the eluate was collected in $13 \mathrm{ml}$ fractions. An enriched complex containing $1(\sim 7 \mathrm{mg})$ was obtained with three injections of $40 \mathrm{mg}$ each of the crude material. The complex was further purified through another HPLC ODS-H80 column, (YMC J'sphere, $4 \mu \mathrm{m}$, $15 \times 100 \mathrm{~mm}$ ). The column was eluted with a two-step gradient of $\mathrm{MeCN}-\mathrm{H}_{2} \mathrm{O}: 3 \sim 50 \% \mathrm{MeCN}$ in 40 minutes, and then $50 \sim 100 \% \mathrm{MeCN}$ over another 10 minutes, with a flow rate of $3 \mathrm{ml} /$ minute and $\sim 2 \mathrm{ml}$ fractions were collected for each fraction. Pure $1(\sim 1.5 \mathrm{mg})$ was obtained, at retention time $\sim 41$ minutes with two injections of $\sim 3.5 \mathrm{mg}$ each of the enriched material.

The structure of 1 was mainly elucidated by extensive 1D and 2D NMR data analyses. In the ${ }^{13} \mathrm{C}$ - and ${ }^{1} \mathrm{H}-\mathrm{NMR}$ spectra, 18 carbon and 29 proton signals were observed, respectively (Table 1 ). The characteristics of the 18 carbon signals were identified as one methyl, one carbonyl, two olefinic methine, four oxygenated-methine, and ten aliphatic methylene carbons on the basis of analyses of ${ }^{1} \mathrm{H}-$ and ${ }^{13} \mathrm{C}$-NMR, and APT and HSQC data. The molecular formula of 1 was therefore established as $\mathrm{C}_{18} \mathrm{H}_{32} \mathrm{O}_{5}$ which is consistent with a positive ESI-MS measurement $(\mathrm{m} / \mathrm{z}$
329, $[\mathrm{M}+\mathrm{H}]^{+}$, performed on a Waters MicromassZQ mass spectrometer). Based on three degrees of unsaturation and only five oxygen atoms in the molecule, a cyclic ring structure through either an ether or ester linkage was proposed.

The multiplicity of the carbons was determined through an APT experiment, and the proton-attached carbon resonances were assigned to the corresponding proton signals by analysis of HSQC data. However proton signals were highly overlapped between $\delta 1.00$ and $1.80 \mathrm{ppm}$ in the ${ }^{1} \mathrm{H}$ NMR spectrum. These could be only interpreted through a two dimensional HSQC-TOCSY spectrum. The HSQC-TOCSY data shown in Table 1 strongly suggested a linear chain moiety based on the analysis of ${ }^{1} \mathrm{H}-{ }^{13} \mathrm{C}$ correlations from $\mathrm{C}-2$ through $\mathrm{C}-18$, which are all proton attached carbons. Thus the locations of double bond $(\Delta 2,3)$, four oxygen atoms (on C-4, C-5, C-7, and C-13), and the terminal methyl group $(\mathrm{C}-18)$ were determined. These assignments were confirmed by HMBC data analysis, as shown in Fig. 1. H-2 ( $\delta 6.07$, dd, $J=15.8$, $1.6 \mathrm{~Hz}$ ) showed a simple coupling pattern in ${ }^{1} \mathrm{H}$ NMR and thus indicated that $\mathrm{C}-2$ was adjacent to the remaining 


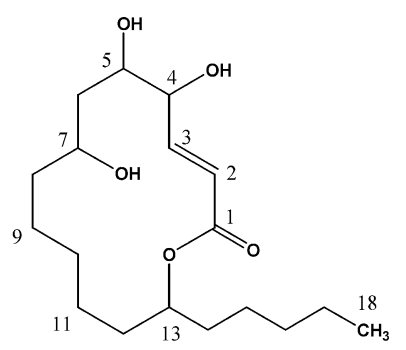

Sch $725674(1)$

Gloeosporone (2)
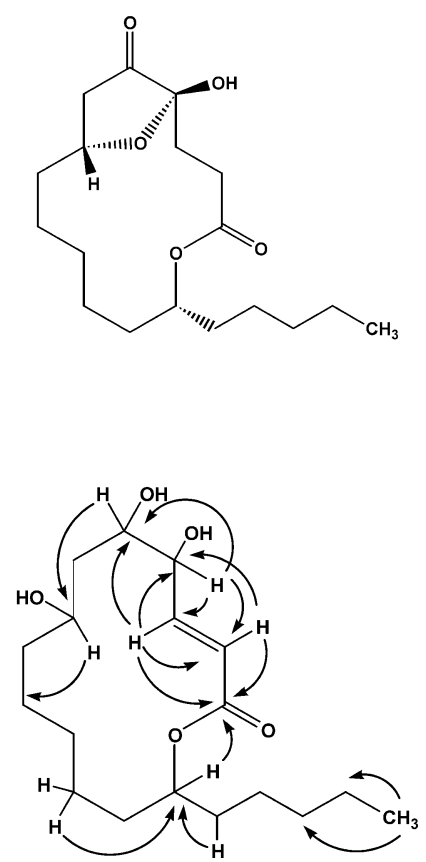

Fig. 1 Structures of 1, 2 and key HMBC correlations of $\mathbf{1}$.

carbonyl carbon $\mathrm{C}-1$. This was confirmed by long-range correlations of H-2 $(\delta 6.07)$ and H-3 $(\delta$ 6.86) to C-1 ( $\delta$ 168.4) on the basis of HMBC data analysis. Finally, the observation of the long-range correlation of H-13 ( $\delta 4.94)$ and $\mathrm{C}-1$ established the ester linkage of the 14-membered macrocyclic ring skeleton.

The coupling constant $(J=15.8 \mathrm{~Hz})$ between $\mathrm{H}-2$ and $\mathrm{H}-$ 3 established the trans configuration of $\Delta 2,3$. Thus, the structural elucidation of $\mathbf{1}$ was completed. Unambiguous assignment of the proton and carbon chemical shifts was achieved based on 2D NMR data analyses including HSQC, HSQC-TOCSY, and HMBC as detailed in Table 1. The stereochemistry of the four oxygenated methines could not be established at this stage due to the limited amount of sample.

Compounds with fourteen-membered macrocyclic mono-lactone skeletons without additional methyl group substitution on the ring (erythromycin-like) are very rare in nature. Gloeosporone (2), the fungal germination selfinhibitor from the fungus Colletotrichum gloeosporioides, is the best known and studied in this class [9, 10]. Gloeosporone has shown antifungal activity [11]. Due to its interesting biological activity gloeosporone and its stereo isomers have been chemically synthesized through different routes [11 15]. To the best of our knowledge, compound $\mathbf{1}$ is the second member in this class without a highly branched skeleton chain.

Sch725674 (1) displayed antifungal activity against Saccharomyces cerevisiae (PM503) [16] and Candida albicans (C43) with MICs 8 and $32 \mu \mathrm{g} / \mathrm{ml}$, respectively. Compound $\mathbf{1}$ did not show antibacterial activity against Staphylococcus aureus and Escherichia coli at levels up to $256 \mu \mathrm{g} / \mathrm{ml}$.

Acknowledgement The authors are grateful to Mr. Lewis B. Fan for extract preparation.

\section{References}

1. Yang SW, Buevich A, Chan TM, Terracciano J, Chen G, Loebenberg D, Patel M, Boehm E, Gullo V, Pramanik B, Chu M. A new antifungal sterol sulfate, Sch 601324, from Chrysosporium sp. J Antibiot 56: 419-422 (2003)

2. Yang SW, Chan TM, Pomponi SA, Gonsiorek W, Chen G, Wright AE, Hipkin W, Patel M, Gullo V, Pramanik B, Zavodny P, Chu M. A new sesterterpene, Sch 599473, from a marine sponge, Ircinia sp. J Antibiot 56: 783-786 (2003)

3. Yang SW, Chan TM, Pomponi SA, Chen G, Wright AE, Patel M, Gullo V, Pramanik B, Chu M. A new bicyclic guanidine alkaloid, Sch 575948, from a marine sponge, Ptilocaulis spiculifer. J Antibiot 56: 970-972 (2003)

4. Yang SW, Chan TM, Terracciano J, Loebenberg D, Chen G, Patel M, Gullo V, Pramanik B, Chu M. Structure elucidation of a new diketopiperazine Sch 725418 from Micromonospora sp. J Antibiot 57: 345-347 (2004)

5. Yang SW, Chan TM, Terracciano J, Patel R, Loebenberg D, Chen G, Patel M, Gullo V, Pramanik B, Chu M. A new anthracycline antibiotic micromonomycin from Micromonospora sp. J Antibiot 57: 601-604 (2004)

6. Yang SW, Xu L, Mierzwa R, He L, Terracciano J, Patel M, Gullo V, Black T, Zhao W, Chan TM, Chu M. Two novel antibiotics, Sch 419558 and Sch 419559, produced by Pseudomonas fluorescens: effect on activity by overexpression of RpoE. Bioorg Med Chem 12: 3333-3338 (2004)

7. Yang SW, Chan TM, Patel R, Terracciano J, Loebenberg D, Patel M, Chu M. A new antimicrobial dibenzofuran Sch 725421 from an unidentified fungus. J Antibiot 57: 465-467 (2004)

8. Yang SW, Chan TM, Terracciano J, Patel R, Loebenberg D, Chen G, Patel M, Gullo V, Pramanik B, Chu M. New 
antibiotic Sch 725424 and its dehydration product Sch 725428 from Kitasatosporia sp. J Antibiot 192-195 (2005)

9. Meyer WL, Lax AR, Templeton GE, Brannon MJ. The structure of gloeosporone, a novel germination self-inhibitor from conidia of Colletotrichum gloeosporioides. Tetrahedron Lett 24: 5059-5062 (1983)

10. Meyer W, Schweizer WB, Beck AK, Scheifele W, Seebach D, Schreiber SL, Kelly SE. 31. Revised structure of the fungal germination self-inhibitor gloeosporone. Helv Chim Acta 70: 281-291 (1987)

11. Seebach D, Adam G, Zibuck R, Simon W, Rouilly M, Meyer WL, Hinton JF, Privett TA, Templeton GE, Heiny DK, Gisi $\mathrm{U}$, Binder H. Gloeosporone-a macrolide fungal germination self-inhibitor total synthesis and activity. Liebigs Ann Chem 1233-1240 (1989)

12. Matsushita M, Yoshida M, Zhang Y, Miyashita M, Irie H, Ueno T, Tsurushima T. Synthesis of a germination selfinhibitor, (-)-gloeosporone, and related compounds and evaluation of their activities. Chem Pharm Bull 40: 524-527 (1992)

13. Schreiber SL, Kelly SE, Porco JA Jr., Sammakia T, Suh EM. Structural and synthetic studies of the spore germination autoinhibitor gloeosporone. J Am Chem Soc 110: 6210-6218 (1988)

14. Adam G, Zibuck R, Seebach D. Total synthesis of (+)-gloeosporone: assignment of absolute configuration. J Am Chem Soc 109: 6176-6177 (1987)

15. Furstner A, Langemann K. Total syntheses of $(+)$-ricinelaidic acid lactone and of (-)-gloeosporone based on transition-metal-catalyzed $\mathrm{C}-\mathrm{C}$ bond formation. J Am Chem Soc 119: 9130-9136 (1997)

16. Yang SW, Chan TM, Pomponi SA, Chen G, Loebenberg D, Wright A, Patel M, Gullo V, Pramanik B, Chu M. Structure elucidation of a new antifungal sterol sulfate, Sch 575867 , from a deep-water marine sponge (Family: Astroscleridae). J Antibiot 56: 186-189 (2003) 